\title{
Evaluation of the Effect of Teeth Whitening Strips on Dental Plaque $\mathrm{pH}$
}

\author{
Hoorizad Ganjkar $\mathbf{M}^{1}$, Heshmat $\mathbf{H}^{2}$, Hedayat $\mathbf{N}^{3 *}$ \\ ${ }^{1}$ Assistant Professor, Restorative Dentisitry Dept, Dental Material Research Center,Dental Branch of Tehran, Islamic Azad University, Tehran, Iran \\ ${ }^{2}$ Associate Professor, Restorative Dentisitry Dept, Dental Material Research Center,Dental Branch of Tehran, Islamic Azad University, Tehran, Iran \\ ${ }^{3}$ Post Graduate Student,Restorative Dentisitry Dept, Dental Branch of Tehran, Islamic Azad University, Tehran, Iran
}

\begin{tabular}{l}
\hline ARTICLE INFO \\
\hline Article Type \\
Original Article \\
\hline Article History \\
Received: June 2016 \\
Accepted: Dec 2016 \\
ePublished: Jan 2017 \\
\hline Keywords: \\
Tooth bleaching, \\
Dental plaque, \\
pH
\end{tabular}

\section{AbSTRACT}

Background and aim:The present study aimed to assess the effect of teeth whitening strips on dental plaque $\mathrm{pH}$ in vivo.

Materials and methods: This in vivo experimental study was conducted on 21 individuals, who were requested to use Crest 3D whitening strips for 30 minutes once a day and for 14 days according to the manufacturer's instructions. Dental plaque $\mathrm{pH}$ was measured using GC plaque indicator kit at baseline (before using the strip), immediately after use (upon removal of the strip), and 30 minutes after the treatment at days one, seven and 14 following the onset of bleaching treatment. The data were analyzed using Freidman test, while Dunn's post-hoc analysis was used for complete comparison.

Results: At days one, 7 and 14, the plaque $\mathrm{pH}$ decreased immediately after the completion of the treatment compared to the baseline value, and this reduction was statistically significant $(\mathrm{p}=0.001)$. The $\mathrm{pH}$ increased to the baseline value after 30 minutes. The plaque $\mathrm{pH}$ decreased at the 14th day in comparison with the first day, and this reduction was statistically significant $(\mathrm{p}=0.008)$.

Conclusion: the results of the present study showed that application of whitening strips decreases the plaque $\mathrm{pH}$ immediately after the completion of the treatment; however, 30 minutes after strip removal, the $\mathrm{pH}$ reaches the baseline level. The plaque $\mathrm{pH}$ decreased during the two-week treatment period; however, it did not reach the critical $\mathrm{pH}$.

\footnotetext{
Please cite this paper as: Hoorizad M, Heshmat H, Hedayat N. Evaluation of the Effect of Teeth Whitening Strips on Dental Plaque pH. J Res Dent Maxillofac Sci. 2017;2(1):30-35.
}

*Corresponding author:

Hedayat $\mathbf{N}$

Email: hedayatniloofar@yahoo.com 


\section{Introduction:}

Vital tooth bleaching was first introduced in 1868 , and has gained increasing popularity since then. ${ }^{(1)}$ The home bleaching technique was first introduced to esthetic dentistry in 1989 and since then, Carbamide Peroxide (CP) has been commonly used for this purpose. Despite some insignificant side effects, the efficacy and safety of CP-containing bleaching agents have been well documented. ${ }^{(2-5)}$

Bleaching trays are conventionally used for home bleaching. Teeth whitening strips were introduced to the market to overcome the shortcomings of the tray-based technique with reportedly easier use and superior efficacy. ${ }^{(6,7)}$ Teeth whitening strips available in the market have 0.1 to $0.2 \mathrm{~mm}$ thickness and contain $6 \%$ and $14 \%$ hydrogen peroxide (HP). These strips are made of polyethylene and are flexible. They adhere to labial surfaces of the teeth and release active whitening agents (for 5 to 60 minutes). They must be used once or twice a day for 14 to 28 days to exert their whitening effect. The whitening efficacy of these strips has been reported to be equal to that of bleaching trays containing $10 \%$ $\mathrm{CP}{ }^{(8)}$; however, use of tray is often associated with greater postoperative tooth hypersensitivity. (9) It should be noted that $10 \%$ CP gel contains $3.3 \% \mathrm{HP}$, which is half the concentration of HP in the strips $(6 \%)$; however, a higher volume of gel is placed in the tray compared to the active ingredients present in the strips. Due to easy use, availability, low cost and optimal esthetic results, whitening strips have become increasingly popular in the United States. ${ }^{(10)}$ Also, the whitening potential of these strips is higher than that of other over-the-counter (OTC) tooth whitening products such as mouthrinses and gels. ${ }^{(7)}$

Tooth bleaching agents have different $\mathrm{pH}$ values depending on their chemical formulation. ${ }^{(11)}$ However, OTC bleaching agents often have a low $\mathrm{pH}^{(12)}$ The changes in the plaque $\mathrm{pH}$ following the use of bleaching agents can alter enamel structure and can lead to initiation or cessation of carious lesions development, increasing the surface roughness while decreasing the surface hardness. ${ }^{(13)}$ One study showed a significant increase in the $\mathrm{pH}$ of dental plaque and saliva fol- lowing the use of $10 \% \mathrm{CP}$ for dental bleaching ${ }^{(14)}$, while another study reported increased accumulation of dental plaque following a five-day period of no tooth brushing after tooth bleaching with $35 \%$ HP. $^{(15)}$

Evidence shows that bleaching agents including whitening strips can cause changes in tooth structure. ${ }^{(16,17)}$ However, some other studies have reported that the changes in tooth structure due to application of whitening agents are insignificant. ${ }^{(18)}$ Considering the lack of information on the effects of whitening strips on dental plaque $\mathrm{pH}$, this study aimed to assess the effect of Crest $3 \mathrm{D}$ whitening strips on dental plaque $\mathrm{pH}$ in vivo.

\section{Materials and methods:}

This experimental in vivo study was conducted on 21 individuals, who were selected from among the students of the dental school of Islamic Azad University, using consecutive sampling. The inclusion criteria were the age range of 20-24 years, absence of periodontal disease, caries or dental restorations and willingness to use whitening strips. The study protocol was approved by the ethics committee of the university, and the participants signed written informed consent forms. The sample size was calculated based on a pilot study with the ethics code IR.IAU. DENTAL.REC.1395,24.

The participants were requested to refrain from eating, drinking, using mouthwashes or tooth brushing for two hours prior to the experiment. Plaque $\mathrm{pH}$ was measured at the baseline using a plaque indicator kit (GC, Suzhou, China). The plaque was collected from the cervical area of second right mandibular premolar. Immediately prior to plaque sample collection, an air syringe was used to lightly dry the sampling site to reduce the risk of contamination with saliva. The plaque sample was dipped for 1 second into an indicator solution and was observed after 5 minutes and its color was checked. The color should be compared with the testing chart available in the package as follows: Green $(\mathrm{pH}>6.8)$, yellow $(6.4<\mathrm{pH}<6.8)$, orange $(5.8<\mathrm{pH}<6.4)$, and red $(\mathrm{pH}<5.8)$. The participants were then instructed on how to use whitening strips (Crest 3D White Advanced Vivid White strips, OH, USA) 
and were requested to use the strips for $30 \mathrm{~min}$ utes once a day and for 14 days. After 30 minutes, the strip was removed from the mouth and the plaque $\mathrm{pH}$ was measured immediately after removal of the strip, and also 30 minutes later at days one, seven and 14.

The collected data were analyzed using Freidman test, while Dunn's post-hoc analysis was used for complete comparison.

\section{Result:}

Freidman analysis showed that at the first day, the plaque $\mathrm{pH}$ decreased immediately after the completion of the treatment compared to the baseline value $(p=0.001)$. Also, at days 7 and 14 , the plaque $\mathrm{pH}$ decreased immediately after the completion of the treatment compared to the baseline value $(\mathrm{p}=0.002) .30$ minutes after the treatment, the plaque $\mathrm{pH}$ increased to the level of the baseline $\mathrm{pH}$ at days one, 7 and 14. The results are presented in Table 1.
Assessment of the baseline plaque $\mathrm{pH}$ with Dunn's test showed that the baseline plaque $\mathrm{pH}$ at the 14th day was lower than that at days one and 7 , and this reduction was statistically significant $(p=0.005)$. However, the reduction in the baseline plaque $\mathrm{pH}$ at the 7 th day was not significant compared to the first day $(\mathrm{P}=0.547)$.

At the 14th day, the plaque $\mathrm{pH}$ immediately after the treatment was lower than that at the first and 7 th days, and this difference was statistically significant $(\mathrm{P}=0.032)$. The plaque $\mathrm{pH} 30$ minutes after the treatment at the 14th day was lower than that at the first and 7th days, and this difference was statistically significant $(\mathrm{P}=0.008)$. (Tables 2 , 3 and 4)

Table 1- Plaque pH at days one, 7 and 14, at three different time intervals (baseline, immediately, and 30 minutes after the treatment)

\begin{tabular}{|c|c|c|c|c|c|c|}
\hline \multicolumn{2}{|c|}{ Day } & Green $(\mathrm{pH}>6.8)$ & Yellow $(6.4<\mathrm{pH}<6.8)$ & Orange $(5.8<\mathrm{pH}<6.4)$ & $\operatorname{Red}(\mathrm{pH}<5.8)$ & p. value \\
\hline \multirow[b]{3}{*}{$1^{\text {st }}$} & Before & 8 & 10 & 3 & --- & \\
\hline & After & 1 & 9 & 8 & 3 & \\
\hline & $\begin{array}{c}30 \\
\text { minute } \\
\text { s later }\end{array}$ & 7 & 10 & 3 & 1 & .001 \\
\hline \multirow[b]{3}{*}{ 7th } & Before & 6 & 11 & 3 & 1 & \multirow[b]{3}{*}{.002} \\
\hline & After & 3 & 8 & 7 & 3 & \\
\hline & $\begin{array}{c}30 \\
\text { minute } \\
\text { s later }\end{array}$ & 8 & 7 & 6 & --- & \\
\hline & Before & 1 & 10 & 10 & --- & \\
\hline & After & --- & 6 & 9 & 6 & \\
\hline 14th & $\begin{array}{c}30 \\
\text { minute } \\
\text { s later }\end{array}$ & 2 & 8 & 9 & 2 & .002 \\
\hline
\end{tabular}

Table 2- Comparison of the plaque $\mathrm{pH}$ at days one, 7 and 14, at the baseline (before the treatment)

\begin{tabular}{ccccc}
\hline $1^{\text {st }}$ & Green $(\mathrm{pH}>6.8)$ & Yellow $(6.4<\mathrm{pH}<6.8)$ & $\operatorname{Orang}(5.8<\mathrm{pH}<6.4)$ & $\operatorname{Red}(\mathrm{pH}<5.8)$ \\
\hline $7^{\text {th }}$ & 8 & 10 & 3 & -005 \\
\hline $14^{\text {th }}$ & 6 & 11 & 3 & 1 \\
\hline
\end{tabular}


Table 3- Comparison of the plaque pH at days one, 7 and 14, immediately after the treatment

\begin{tabular}{cccccc}
\hline Sample & Green $(\mathrm{pH}>6.8)$ & Yellow $(6.4<\mathrm{pH}<6.8)$ & Orang $(5.8<\mathrm{pH}<6.4)$ & Red $(\mathrm{pH}<5.8)$ & p. value \\
\hline $1^{\text {st }}$ & 1 & 9 & 8 & 3 & .032 \\
\hline $7^{\text {th }}$ & 3 & 8 & 7 & 3 \\
\hline $14^{\text {th }}$ & -------- & 6 & 9 & 6 \\
\hline
\end{tabular}

Table 4- Comparison of the plaque $\mathrm{pH}$ at days one, 7 and 14, 30 minutes after the treatment

\begin{tabular}{|c|c|c|c|c|c|}
\hline $\begin{array}{r}\text { pH } \\
\text { Sample } \\
\end{array}$ & $\operatorname{Green}(\mathrm{pH}>6.8)$ & Yellow $(6.4<$ pH $<6.8)$ & Orang $(5.8<\mathrm{pH}<6.4)$ & $\operatorname{Red}(\mathrm{pH}<5.8)$ & p. value \\
\hline $1^{\text {st }}$ & 7 & 10 & 3 & 1 & .008 \\
\hline $7^{\text {th }}$ & 8 & 7 & 6 & --------- & \\
\hline $14^{\text {th }}$ & 2 & 8 & 9 & 2 & \\
\hline
\end{tabular}

\section{Discussion:}

The present study assessed the effects of teeth whitening strips on dental plaque $\mathrm{pH}$, and showed that the use of whitening strips significantly decreases dental plaque $\mathrm{pH}$ at days one, 7 and 14, immediately after removal of the strip.

In this study, 3D White Advanced Vivid White strips were used, which contain 9.5\% HP loaded on polyethylene strips. According to the material safety datasheet, the $\mathrm{pH}$ of these whitening strips is $5 .^{(19)}$ These adhesive strips expose the labial enamel surface to the whitening agents loaded on the strips, which release HP shortly after contacting the teeth (for 5 to 60 minutes). Evidence shows that the whitening efficacy of these strips is similar to that of other tooth whitening products, except that postoperative tooth hypersensitivity is often greater after the use of tray-based systems, which may be attributed to the composition of the whitening agents used or to maladaptation of the tray margins with the soft tissue adjacent to the teeth. ${ }^{(20)}$

In the current study, the selected participants had relatively favorable oral hy- giene and their baseline plaque $\mathrm{pH}$ values were above the critical $\mathrm{pH}$ of 5.5. The baseline plaque $\mathrm{pH}$ of the subjects at the first day ranged from 6 to 7.2 . In $70 \%$ of the participants, the plaque $\mathrm{pH}$ was 6 to 6.6 prior to the treatment. This value significantly decreased after using the strips, which indicated the effect of time on the plaque $\mathrm{pH}$ changes following the use of bleaching agents. The duration of bleaching treatment in the current study was 14 days as recommended by the manufacturer, and the plaque $\mathrm{pH}$ did not decrease to below the critical $\mathrm{pH}$ during this period and remained in the range of 6 to 6.4. Hourizad and Heshmat evaluated the effect of whitening strips on the $\mathrm{pH}$ of saliva in vivo and found that despite the acidic $\mathrm{pH}$ of the strips $(\mathrm{pH}=5)$, no significant changes occurred in the salivary $\mathrm{pH}$, which was attributed to the strong buffering capacity of saliva. ${ }^{(21)}$

Our results showed that the use of whitening strips for 14 days significantly decreased the dental plaque $\mathrm{pH}$ compared to day one, although this reduction did not reach the critical $\mathrm{pH}$. According to the Stephan Curve, the plaque $\mathrm{pH}$ decreases faster than the salivary $\mathrm{pH}$ after exposure to acid, and slowly returns to the baseline value. ${ }^{(22)}$ This faster reduction in the $\mathrm{pH}$ may be attributed to the 
fact that dental plaque may serve as a barrier and may prevent the penetration of the saliva buffering system into the plaque. ${ }^{(22)}$ Although the buffering capacity of saliva is lower in dental plaque, its effect is still obvious. The most important factor that prevents the reduction of the plaque $\mathrm{pH}$ to below the critical threshold $(\mathrm{pH}<5.5)$ is the saliva, as it contains calcium and phosphate ions. This is one of the reasons of the differences between in vivo and in vitro studies. In vitro studies always show higher roughness and different $\mathrm{pH}$ changes in comparison with in vivo studies. ${ }^{(23)}$

Leonard et al, evaluated the changes in the plaque $\mathrm{pH}$ following the use of $10 \% \mathrm{CP}$ in nightguard bleaching of vital teeth, and concluded that the plaque $\mathrm{pH}$ and salivary $\mathrm{pH}$ significantly increased compared to the baseline values and remained high for two hours. ${ }^{(14)}$ However, in the current study, the plaque $\mathrm{pH}$ decreased following the use of whitening strips. Such controversy in the results of the two studies may be due to the differences in the composition of the applied bleaching agents. Whitening strips contain HP, which has acidic $\mathrm{pH}$ due to the presence of conservatives. However, $\mathrm{CP}$ as a bleaching agent quickly breaks down into urea and HP, and urea increases the $\mathrm{pH}$ of the oral cavity to $>8$ for a couple of hours. ${ }^{(24)}$

Lazarchik et al, Thomas et al, Zheng et al, and Ittatirut et al evaluated the effects of whitening agents on the salivary $\mathrm{pH}$, plaque adhesion and cariogenic microorganisms and found that bleaching agents decreased plaque accumulation and cariogenic microorganism count. ${ }^{(25-28)}$ Thus, in addition to their beneficial whitening effects, these compounds may be recommended to certain patients. On the other hand, HP compounds may change the structure of dental plaque due to their acidic nature. ${ }^{(13)}$ According to $\mathrm{Xu}$ et al, the probable destructive effects of these strips on dental structure may be attributed to the reduction of the plaque $\mathrm{pH}$ following the use of these strips. ${ }^{(29)}$ Thus, these products must be used cautiously under the supervision of dental clinicians. Considering the acidic nature of whitening strips, if they are used incorrectly by patients with poor oral hygiene without the supervision of dentists or accompanied by a nutritional regimen rich in carbohydrates or acidic drinks, the changes in the plaque $\mathrm{pH}$ may adversely affect the enamel structure and may make the teeth susceptible to caries.
Similar studies are required on the patients with high risk for caries. Also, assessment of the plaque $\mathrm{pH}$ for longer periods of time following the use of bleaching products is recommended. The effects of other OTC bleaching products on dental plaque $\mathrm{pH}$ should also be evaluated and compared with those of whitening strips.

\section{Conclusions:}

Based on the results of the present study, application of bleaching strips decreases the plaque $\mathrm{pH}$, although this reduction does not reach the critical $\mathrm{pH}$. Nevertheless, it is necessary to consider the other factors that can decrease the plaque $\mathrm{pH}$ and increase the risk for caries during the bleaching period such as oral hygiene and nutritional regimen (use of acidic foods and drinks must be limited).

Acknowledgments:The authors would like to thank the Dental research center of Tehran University of Medical Sciences and The AFM center of Iran University of Science and Technology for the laboratory work.

Conflict of interests: Authors report no conflict of interest related to this study.

\section{References:}

1.Price RB, Sedarous M, Hiltz GS. The $\mathrm{pH}$ of tooth-whitening products. J Can Dent Assoc 2000;66(8):421-6.

2.Almeida LC, Riehl H, Santos PH, Sundfeld ML, Briso AL. Clinical evaluation of the effectiveness of different bleaching therapies in vital teeth. Int J Periodontics Restorative Dent 2012;32(3):303-9.

3.Bernardon JK, Sartori N, Ballarin A, Perdigão J, Lopes GC, Baratieri LN. Clinical performance of vital bleaching techniques. Oper Dent 2010;35(1):3-10.

4.He LB, Shao MY, Tan K, Xu X, Li JY. The effects of light on bleaching and tooth sensitivity during in-office vital bleaching: A systematic review and meta-analysis. J Dent 2012;40(8):644-53.

5.Wetter NU, Branco EP, Deana AM, Peli- 
no JE. Color differences of canines and incisors in a comparative long-term clinical trial of three bleaching systems. Lasers Med Sci 2009;24(6):941-7.

6.Demarco FF, Meireles SS, Masotti AS. Overthe-counter whitening agents: a concise review. Braz Oral Res 2009;23(1):64-70.

7.Gerlach RW, Gibb RD, Sagel PA. A randomized clinical trial comparing a novel 5.3\% hydrogen peroxide whitening strip to $10 \%, 15 \%$, and $20 \%$ carbamide peroxide tray-based bleaching systems. Compend Contin Educ Dent Suppl 2000;29:S22-8.

8.Serraglio CR, Zanella L, Dalla-Vecchia KB, Rodrigues-Junior SA. Efficacy and safety of over-the-counter whitening strips as compared to home-whitening with $10 \%$ carbamide peroxide gel--systematic review of RCTs and metanalysis. Clin Oral Investig 2016;20(1):1-14.

9.Auschill TM, Hellwig E, Schmidale S, Sculean A, Arweiler NB. Efficacy, side-effects and patients' acceptance of different bleaching techniques (OTC, in-office, at-home). Oper Dent 2005;30(2):156-63.

10.Donly KJ, Gerlach RW. Clinical trials on the use of whitening strips in children and adolescents. Gen Dent 2002;50(3):242-5.

11.Price RB, Sedarous M, Hiltz GS. The $\mathrm{pH}$ of tooth-whitening products. J Can Dent Assoc 2000;66(8):421-6.

12.Majeed A, Grobler SR, Moola MH. The $\mathrm{pH}$ of various tooth-whitening products on the South African market. SADJ 2011;66(6):278-81.

13.Alqahtani MQ. Tooth-bleaching procedures and their controversial effects: A literature review. Saudi Dent J 2014;26(2):33-46.

14.Leonard RH Jr, Austin SM, Haywood VB, Bentley CD. Change in $\mathrm{pH}$ of plaque and $10 \%$ carbamide peroxide solution during nightguard vital bleaching treatment. Quintessence Int 1994;25(12):819-23.

15.Gursoy UK, Eren DI, Bektas OO, Hurmuzlu F, Bostanci V, Ozdemir H. Effect of external tooth bleaching on dental plaque accumulation and tooth discoloration. Med Oral Patol Oral Cir Bucal 2008 1;13(4):E266-9.

16.Basting RT, Rodrigues AL Jr, Serra MC. The effects of seven carbamide peroxide bleaching agents on enamel microhardness over time. J Am Dent Assoc 2003;134(10):1335-42.

17.Gladwell J, Simmons D, Wright JT. Remin- eralization potential of a fluoridated carbamide peroxide whitening gel. J EsthetRestor Dent 2006;18(4):206-12.

18.Smidt A, Feuerstein O, Topel M. Mechanical, morphologic, and chemical effects of carbamide peroxide bleaching agents on human enamel in situ. Quintessence Int 2011;42(5):407-12.

19.Zimmerman B,Datko 1, Cupelli M ,Alapati S, Dean D ,Kennedy M.Alteration of dentin enamel mechanical properties due to dental whitening treatments. J Mech Behav Biomed Mater 2010;3(4):339-46.

20.Gerlach RW, Zhou X, McClanahan SF. Comparative response of whitening strips to a low peroxide and potassium nitrate bleaching gel. Am J Dent 2002;15:19A-23A.

21.Hoorizad M ,Heshmat H ,Poor nazari L .Effect of hydrogen peroxide white strip on saliva PH (invivo).J Res Dent Sci 2014;11(1):1-6.

22.Bowen WH. The Stephan Curve revisited. Odontology 2013;101(1):2-8.

23. Pinto CF, Oliveira Rd, Cavalli V, Giannini M.peroxide bleaching agent effects on Enamel surface microhardness ,roughness and morphology. Braz Oral Res 2004;18(4):306-11.

24. Matis BA, Cochran MA, Wang G, Eckert GJ. A clinical evaluation of two in-office bleaching regimens with and without tray bleaching. Oper Dent 2009;34(2):142-9.

25.Lazarchik DA, Haywood VB. Use of tray-applied 10 percent carbamide peroxide gels for improving oral health in patients with special-care needs. J Am Dent Assoc 2010;141(6):639-46.

26.Thomas EL, Milligan TW, Joyner RE, Jefferson MM. Antibacterial activity of hydrogen peroxide and the lactoperoxidase-hydrogen peroxide-thiocyanate system against oral streptococci. Infect Immun 1994;62(2):529-35.

27.Zheng CY, Pan J, Wang L, Zhang CF. Effects of hydrogen peroxide-containing bleaching on cariogenic bacteria and plaque accumulation. Chin J Dent Res 2011;14(1):47-52.

28.Ittatirut S,Matangkasombut O,Thanyasrisung P.In-office bleaching gel with $35 \%$ hydrogen peroxide enhanced biofilm formation of early colonizing streptococci on human enamel. J Dent 2014;42(11):1480-6.

29.Xu B, Li Q, Wang Y. Effects of $\mathrm{pH}$ values of hydrogen peroxide bleaching agents on enamel surface properties. Oper Dent 2011;36(5):55462. 